EDITOR'S

CHOICE

Correspondence to:

Dr Tom Walker, Centre for

Professional Ethics, Keele

University, Keele, Staffordshire

ST5 5BG, UK; t.walker@peak.

keele.ac.uk

Received 29 August 2008

Accepted 24 November 2008

\title{
What principlism misses
}

\author{
Tom Walker
}

\section{ABSTRACT}

Principlism aims to provide a framework to help those working in medicine both to identify moral problems and to make decisions about what to do. For it to meet this aim, the principles included within it must express values that all morally serious people share (or ought to share), and there must be no other values that all morally serious people share (or ought to share). This paper challenges the latter of these claims. I will argue that as a descriptive claim about what values morally serious people do in fact share, principlism is inadequate; more principles would be needed to make this claim true. Furthermore, I will argue that while, taken as a claim about what principles we ought to share, principlism could turn out to be correct, it is either unsupported or unable to meet its aims. The only way in which principlists can avoid these problems is to add to the current four principles.

Principlism has proved a popular framework for thinking about medical ethics, and often forms part of the education for those coming into medicine. It is not intended to be a general moral theory, but rather aims to provide a framework to help those working in medicine both to identify moral problems and to make decisions about what to do (Beauchamp and Childress, 2001, p15). ${ }^{1}$ Beauchamp and Childress argue that the four principles that are included in principlism (respect for autonomy, non-maleficence, beneficence and justice) express "the general values underlying rules in the common morality" (p12), where the common morality is "the set of norms that all morally serious persons share" (p3). Similarly, Raanan Gillon has claimed that the four principles can explain and justify all the substantive and universalisable moral claims in medical ethics and, he suspects, in ethics more generally. ${ }^{2}$ Furthermore, he goes on to issue a challenge to disprove this thesis by showing either that no additional principle or principles are necessary or that more are needed. This paper is a response to that challenge. While I will not challenge the claim that all the principles are necessary, I will challenge the claim that they are sufficient.

There is, however, some ambiguity here. As Beauchamp and Childress themselves recognise, in making claims about moral norms that are universalisable or about the norms that morally serious persons share, we could be making claims of different types (pp3-5). ${ }^{1}$ On the one hand, we could be making a descriptive claim about what moral norms are in fact shared by all morally serious people; on the other, we could be making a normative claim about what moral norms ought to be shared. Beauchamp and Childress appear to accept both these claims about the common morality, but in developing their principlist approach they take themselves to be making a claim of the normative type. I will come to consider this normative claim later, but first I think it will be useful to say something about the descriptive claim.

\section{WHAT PRINCIPLES ARE UNIVERSALLY SHARED?}

As a descriptive claim, principlism would be true if it expresses the moral norms that are in fact shared by all morally serious people. That is, when thinking seriously about what we ought to do, we all, no matter what our cultural background, recognise moral norms that are captured by the principles of respect for autonomy, non-maleficence, beneficence and justice (though we may disagree about the scope of these). As I have said, I do not intend to challenge this claim. But if four principles are to be enough, then it must also be the case that when we are thinking seriously about what we ought to do, we do not all recognise moral norms that are not captured by these four principles. Recent work in anthropology and social psychology casts doubt on this claim. ${ }^{34}$

It will be useful here to start with a distinction made by Richard Shweder and his colleagues based on their work in India and the USA. They identify what they call three "ethics": the ethics of autonomy (which uses concepts such as harm, justice and autonomy), the ethics of community (which makes use of concepts such as duty, respect and interdependency), and the ethics of divinity (which relies on concepts such as tradition and purity). ${ }^{3}$ On the basis of this experimental work it is argued that all cultures make use of these three ethics, although they may vary in the weight they give to each one. For example, the evidence suggests that well-educated, liberal, secular Westerners place much more weight on, and give much more prominence to, the ethics of autonomy than do others. ${ }^{4}$ This may explain why within the academic world, whether in psychology or philosophy, there has been a focus on the ethics of autonomy. ${ }^{5}$ One of the major conclusions from this experimental work has been that this narrow focus is unrepresentative of what people take to be included in morality. However, having said all this, even those within this particular subculture do not ignore the ethics of community or the ethics of divinity, or deny that there are moral rules and norms in these areas-even if they consider them less weighty than those concerning harm and fairness.

It may be useful to give some examples at this point of the kinds of moral judgement and moral norms that exist outside the ethics of autonomy. Within the ethics of community one norm concerns respect (where this is not limited to respect for autonomy) - we might, roughly, 
characterise it as the principle that one ought to show appropriate respect. Failure to do so would be immoral. If you were, for example, to urinate on a memorial to the dead, then most people would consider you to have acted immorally-and the reason for this is that you would have acted in a way that fails to show respect. Of course, there will be disagreements about who is owed respect (does it include only the living, for example, or do we have a moral duty to respect the dead), and about what would show respect, but in this it is on a par with the existing four principles, where there is similar disagreement about their scope. Within the ethics of divinity, there are moral norms about purity-something like an expectation that one ought not to act in a way that defiles oneself or others. So, for most people, bestiality is morally wrong, and this is not because it violates one of the four principles-ie, the reason it is morally wrong is not that it is unfair, that it fails to be beneficent, that it fails to respect autonomy (the animal is not autonomous in the right way) or that it causes harm (this is not to say that it doesn't cause harm, just that if one removed the harm, bestiality would still be morally wrong).

If this is right, then the four principles included in principlism simply cannot capture the moral norms that are part of the common morality. Those principles are all squarely within the ethics of autonomy, and, indeed, may well be sufficient to express the moral norms that people agree lie within it. While, if we retain our normal academic focus this may look as if it covers the ground of shared moral norms, once we recognise the existence of these other ethics we can see that this is a mistake.

It may, however, be thought that I have somewhat mischaracterised principlism here. I have been concerned with ethics in general, whereas principlism is concerned primarily with medical ethics. Thus, although there are more shared moral norms in this wider sphere, it could still be the case that in medical decision-making the four principles are sufficient to express all the shared moral norms. This is, of course, an empirical claim, and one for which I know of no evidence either way. However, I would not be surprised if it turned out to be true-years of ethics courses for trainee healthcare professionals may well have created a situation in which these four principles are enough to express the moral norms that people think relevant to this area.

But there are two things to say about this, even if it does turn out to be correct. The first is that it would be surprising: if we agree that there are more moral norms than those captured by these four principles, why would people think that those don't apply in the healthcare setting? Second, and more importantly, why should this matter? It may be that in healthcare only a narrow set of moral norms is used, but the issue surely is whether this is sufficient.

\section{WHAT PRINCIPLES OUGHT WE TO SHARE?}

In asking this question, we are moving from considering the claim that the four principles express the moral norms we in fact share to considering the claim that they express the moral norms that we all ought to share. On this account, the common morality establishes "obligatory moral standards for everyone" (Beauchamp and Childress, 2001, p4). ${ }^{1}$ In order for a framework to help us identify moral problems and help us to resolve moral dilemmas, as principlism is designed to do, it must contain all the moral principles that are obligatory for us. If it does not, rather than help us to identify moral problems it will blinker us so that we don't see moral problems that are there. This, I will argue, creates a problem for principlism. What exactly this problem is, however, will depend on whether or not principlists think that all moral norms are universalisable - that is, whether they think that all moral norms are ones that everyone ought to accept.

Suppose principlists hold that all moral norms are universalisable. In that case principlism would be the claim that there are only four principles that are in fact obligatory for us, whoever we are. Such a position implies that much of what most people, including most serious thinkers about the topic, in most cultures take to be matters of morality are in fact not. So, to return to the examples used earlier, things like urinating on a memorial to the dead or bestiality would turn out not to be immoral. Those who think they are would just be mistaken. As such, principlism (in the normative sense) would be a radical challenge to the common morality (in the descriptive sense).

Principlists would appear to have two options here. The first is to expand principlism to include more principles-for example, one of respect and one of purity, as outlined above. In this way it would no longer challenge the common morality. Indeed, such a move would also be an option were we to take principlism as a descriptive account. By adding more principles it would provide a more useful framework for capturing what people think is morally obligatory for them. If, as appears to be the case, one aim of principlism is to provide a framework that people from different cultures can use together to identify what they take to be the moral issues, then this seems to be a useful option.

Alternatively, principlists could hold their ground here and maintain that there are in fact only four moral principles, even if this does challenge the common morality. However, the widespread agreement that there is more to morality than is included under these four principles would appear to create a prima facie case that they are inadequate. As such, if principlists want to take this line they owe us an account of why we should accept that there are only four moral principles (or why there are only four moral principles that are relevant for medical decision-making)

I know of no attempt by principlists to argue along these lines. This is, I think, because in fact principlists do not in general hold that all moral rules and norms are universalisable. They explicitly state that the four principles are not the whole of morality. Beauchamp and Childress, for example, state that, "The universal norms of the common morality comprise only a small set of all actual and possible moral norms ... "morality" in the community-specific sense includes the moral norms that spring from particular cultural, religious and institutional sources" (p3). ${ }^{1}$ And Gillon writes that "Particular cultural and religious obligations may be seen as morally obligatory for members of those cultures and religions but not as morally obligatory for others" (p308). ${ }^{2}$

Just as we can read the claim that principlism expresses the values that all morally serious persons share either as a descriptive or as a normative claim, so there are two ways of reading these claims about culturally specific moral norms. We could take these claims to be descriptive-that is, to read them as saying that people in different cultures take themselves to be bound by moral norms in addition to those included in principlism. Alternatively, we could take them as making normative claims-stating that people in different cultures are in fact bound by moral norms that are culture specific. Either option will create problems for principlism.

Suppose we read the claim that the universal moral norms of the common morality are only a subset of actual moral norms as the descriptive claim that people take themselves to be bound by moral norms other than principlism's four principles. There seems little doubt that this is correct, as was discussed in the 
previous section; however this just raises a further question: "Are people right to take themselves to be bound in this way?" If they are not, then we are back to the position that all moral norms, where this refers to norms that are actually binding on us, are universalisable. People might think there are culturally specific moral norms that are binding on them, but they are wrong about this. This is a defensible position, but it returns us to the problem for principlism outlined earlier in this sectionthat they have given us no reason for thinking that there are only four moral principles.

Principlists could avoid this problem were they to hold that, at least in some cases, people are right to think that there are binding moral norms that are culturally specific. This would be to read the claims made by principlists outlined earlier as normative claims. On such an account, there are two types of binding moral norm: those that are universalisable and binding on everyone, and those that are culture specific and only binding on members of that culture. The four principles would then be the set of moral norms that are universalisablefurthermore, they are the complete set of such norms.

There are two things to note about this. The first is that the position outlined here is at least partially a relativist one-at least some moral norms are culture specific. However, relativism would seem to go against the driving force behind principlism, which was to come up with a framework of moral principles that we could all share. Second, on such an account it seems that principlism will not turn out to be a useful framework for identifying moral issues and making decisions about what we ought to do. This is because on this type of relativist account, in order to identify the moral issues that are binding on me what I need is a set of principles that express the morality of my culture. Principlism provides only a subset of these. This means that if I use only these principles I will miss things that are morally important for members of the culture to which I belong. In shining a spotlight on the principles that are universal, principlism highlights only part of what is morally important for any individual. Indeed, it is worse than this. Principlism may help us to identify moral problems and work through moral dilemmas when they involve its principles. But the light shone on these will tend to throw the other moral principles that are binding on me into the shade. As such, it will be harder for me to identify them than it would be were I not to be using a principlist framework, and moral dilemmas that involve one of the four principles and one of the culture-specific principles will be harder to see as moral dilemmas.

Principlists could avoid this type of problem by moving further towards relativism. What we would need in our culture is a set of principles that covers the moral norms within this culture. What you would need in your culture is a set of principles that cover the moral norms within it. These will overlap (at least for the universal principles and perhaps for some others too) but will not be the same. In this way, it seems, most if not all cultures will have a framework of principles that contains more than four principles. That is, we would need culturally specific forms of principlism if it is to do the job required (as set out by its proponents). This would help members of each culture to identify the moral issues and would be of use in coming to resolve moral dilemmas. Furthermore, it would help us to recognise when people in other cultures are facing a moral dilemma, or to see why they take something as morally important.

However, although culturally specific forms of principlism might help us to identify moral problems and make decisions about what to do, such a move is problematic for principlists, for two reasons. First, more than four principles will be needed in each culturally specific version of principlism, and second, such an account does not provide what it set out to provide: a common framework that individuals from different backgrounds can use. This is not to say that it might not be useful in this latter respect. A focus on only what we share can make it hard to identify when people in other cultures are facing a moral dilemma, or to see what is morally important for them-which, in turn, can lead to misunderstanding and confusion. ${ }^{5}$ Of course, delineating cultures and the moral norms that are binding within them is difficult. But it seems more sensible to attempt this than simply to shore off the principles that vary from culture to culture so that we can get some agreement. Wearing blinkers so that we all see the same isn't the best way to identify problems.

\section{CONCLUSIONS}

What can we conclude from all this? The first thing is that as a descriptive claim about the principles that people hold and that could be important for medical decision-making, principlism is inadequate in that it includes too little. We need more than four principles to adequately capture the common morality. Second, if we take principlism to be an attempt to capture the moral norms that are universalisable, and furthermore to claim that all moral norms are universalisable, then principlists owe us an explanation of why morality is so narrowly constrained. Such an account rules much of what we take to be morally significant as in fact not a matter of morality at all, and there seems little reason to accept this without argument-an argument principlists have not supplied. In the absence of such an argument, principlists would appear to have only two options, both of which would involve expanding the number of principles beyond the current four. They could simply expand the number of universal principles so that they more adequately capture the common morality. Alternatively, they could argue that not all moral norms are universalisable. In the latter case, however, relying on a framework that includes only four principles gets in the way of identifying moral problems and solving many dilemmas. It makes it harder, not easier, to identify the moral obligations I have as a member of a specific culture, even while making it easier to identify my obligations that fall under one of the principles. To avoid this, principlists would need to move to culture-specific versions of principlism - most if not all of which would contain more than the current four principles.

Acknowledgements: I would like to thank Eve Garrard and Allison Ross for their helpful comments on an earlier version of this paper.

Competing interests: None.

Provenance and peer review: Not commissioned; externally peer reviewed.

\section{REFERENCES}

1. Beauchamp T, Childress J. Principles of biomedical ethics, 5th edn. Oxford: Oxford University Press, 2001.

2. Gillon R. Ethics needs principles. J Med Ethics 2003;29:307-12.

3. Shweder R, Much N, Mahapatra M, et al. The "big three" of morality (autonomy, community, divinity) and the "big three" explanations of suffering. In: Brandt A, Rozin P, eds. Morality and health. New York: Routledge, 1997.

4. Haidt $\mathbf{J}$, Joseph $\mathbf{C}$. The moral mind: how five sets of innate intuitions guide the development of many culture-specific virtues, and perhaps even modules. In: Carruthers P, Laurence S, Stich S, eds. The innate mind, vol 3. Oxford: Oxford University Press, 2008.

5. Haidt J, Graham J. When morality opposes justice: conservatives have moral intuitions that liberals may not recognize. Soc Justice Res 2007;20:98-116. 